\title{
A Conversation Analysis of Asking About Disruptions in Method of Levels Psychotherapy
}

Caitlyn Cannon, Joanne Meredith, Susan Speer and Warren

Mansell*

School of Health Sciences, University of Manchester, Manchester, UK

Caitlyn Cannon; University of Manchester

C/O Warren Mansell, School of Health Sciences, Zochonis Building, University

of Manchester, Manchester M13 9PL

Joanne Meredith; University of Manchester ${ }^{1}$

Allerton Building, Room L818, Frederick Road Campus, Salford, M6 6PU. 0161

295 2806, j.m.meredith@salford.ac.uk; http://orcid.org/0000-0001-6834-2005

\footnotetext{
${ }^{1}$ New affiliation - University of Salford
} 
Susan Speer; University of Manchester

School of Health Sciences, Room 1.1, Coupland Building 1, University of Manchester, Manchester, M13 9PL. 0161275 2590, susan.speer@manchester.ac.uk; http://orcid.org/0000-0002-3048-2851

*Warren Mansell; University of Manchester

School of Health Sciences, Zochonis Building, University of Manchester, Manchester M13 9PL. 0161275 8589, warren.mansell@manchester.ac.uk, http://orcid.org/0000-0002-5697-1784

This research received no specific grant from any funding agency, commercial or notfor-profit sectors.

Contribution statement Mansell collected the data and conceived of the idea for the CA study in conjunction with Speer. Cannon conducted the study for her master's thesis, under the supervision of Mansell, Speer and Meredith. Cannon conducted the data trawl and analysed the data in conjunction with Mansell, Speer and Meredith, and prepared the first version of the manuscript. All authors commented on and contributed to successive drafts.

Cannon prepared the final version of the manuscript.

Biographical notes

Caitlyn Cannon - Ms Cannon is a Psychological Wellbeing Practitioner who completed her Masters in Research Methods at University of Manchester. She continues to have interests in research and is currently working on publishing an MOL case series with Warren Mansell. 
Joanne Meredith - Dr Meredith is a social, qualitative and media psychologist. She is broadly interested in online communication, political and scientific talk, and uses discourse and conversation analysis to analyse talk and text.

Susan Speer - Dr Speer is a qualitative psychologist conducting research at the intersection of health psychology, medical sociology and social psychology. Her research uses thematic analysis, discursive psychology, and conversation analysis to investigate clinical communication, research methodology in action and identity, gender and inequality.

Warren Mansell - The focus of Dr Mansell's research is psychological approaches to bipolar disorder, transdiagnostic interventions for mental health problems (e.g. A Transdiagnostic Approach to CBT using Method of Levels Therapy), and Perceptual Control Theory. 


\begin{abstract}
Background: Method of Levels (MOL) is a cognitive therapy with an emerging evidence base. It is grounded in Perceptual Control Theory and its transdiagnostic nature means techniques are widely applicable and not diagnosis-specific. This paper contributes to psychotherapy process research by investigating a key technique of MOL, asking about disruptions, and in doing so aims to explore how the technique works and aid the understanding of related techniques in other psychotherapies. Method: Conversation Analysis (CA) is applied to asking about disruptions in twelve real-life therapeutic interactions.

Findings: Analyses explore how and when therapists ask about disruptions, with examples presented according to their degree of adherence to the MOL approach. The majority of identified instances project responses consistent with MOL aims; encouraging further talk, focused on the client's problem, and with a shift to meta-level commentary. Also presented are examples of therapist and client influence on disruptions.

Conclusion: The paper provides support for a number of MOL practices, with clinical implications and links to other psychotherapies highlighted.
\end{abstract}

Keywords: psychotherapy; psychotherapy process research; control theory; qualitative methods; Conversation Analysis; 


\section{INTRODUCTION}

Establishing how and why psychotherapies work and the processes involved (Kazdin, 2008) is important. Process research allows for the establishment and evaluation of explanations of therapeutic change, rather than solely identifying its existence (Elliott, 2010). Through identifying these mechanisms, it is possible to explore how change is achieved and how best to optimise it (Kazdin, 2008; Pfeifer \& Strunk, 2015). Process research is a key way of ensuring evidencebased practice within health-care services, contributing to improved quality, accountability, outcomes, and better understandings of each of these (Spring, 2007). 
One informative method of process research is to analyse a single component of therapy in detail. Here, we report a conversation analysis of an active component of an emerging psychotherapy - Method of Levels (MOL; Carey, 2006). MOL is a particularly appropriate therapy to analyse in detail as it is based on a unified theory of psychological functioning - Perceptual Control Theory (PCT; Powers, 1973) - and so its techniques are widely applicable. MOL has an emerging evidence base, indicating prepost effect sizes in mental health settings that are equivalent or exceed benchmarked studies of similar settings (Carey, 2009; Carey \& Mullan, 2008; Carey, Tai, \& Stiles, 2013).

MOL is a unique therapy with distinct properties, and yet draws upon principles that are shared across all effective therapies (Carey, Mansell, \& Tai, 2015). Its main distinguishing feature is that every component of MOL is directed by PCT. Control is one key principle of PCT. PCT states that all individuals have a need for control, with behaviour the means for trying to keep subjective experiences as close to preferred experiences as possible (Powers, 1973). The second key principle relates to conflict. PCT states that psychological distress stems from conflict between important personal goals and the lack of control that follows (Carey, 2006). Hierarchical structure is the third key principle. Control and subsequent behaviour are governed by internal control systems that are arranged in a hierarchical fashion. Higher level systems deal with overarching perceptions or goals, with lower levels becoming more concrete and 
specific (Powers, 2009). A high-level goal, for example, might be 'wanting to be happy'; and this could hierarchically feed into lower level goals, such as 'being surrounded by friends', 'organising plans to meet friends', and 'talking to friends' at the lowest level. PCT also provides a unifying explanation of psychological change. MOL exclusively aims to help clients shift awareness to the specific aspects of their problem they wish to talk about and sustain awareness there while exploring and addressing the problem (Carey, 2006). It helps shift awareness 'up levels' of clients' control hierarchies, through the therapist's curious questioning and asking about disruptions in the client's speech (Carey, 2006).

Disruptions in speech occur regularly throughout everyday conversation. It can be any change in speech, mannerism or demeanour that disrupts the stream of words; such as a pause, smile, change in tone or body language (Carey, 2006; Carey et al., 2015). Disruptions relate to PCT views on awareness and its fluidity. Foreground thoughts are seen to represent activity at one level of the internal control system, with background thoughts representing comment or reflection at some higher level (Carey, 2006). A disruption is thought to indicate when a background thought has occurred and come to the foreground, representing a change in awareness, with the individual evaluating, reflecting or concluding something they have just said (Carey, 2006). Asking the client to consider and elaborate on a disruption keeps the background thought in the foreground, enabling the client to shift their awareness up a level in the hierarchy, signifying the intrinsic goal of MOL (Carey, 2006). This leads to a state that can be 
termed 'mindful awareness', serenity or calmness (Carey, 2006; Powers, 2009). Ultimately this process is theorised to help clients become more aware of their internal goals and conflicts, develop new insights, regain control and facilitate psychological change (Carey, 2006). As clients progress through sessions, it is theorised that they develop greater mental flexibility, becoming able to recognise these background thoughts, goals and conflicts (Carey, 2006). This client-led nature of MOL means it is suitable for, and effective in, a wide range of settings (Carey, Carey, Mullan, Spratt, \& Spratt, 2009). When asking about disruptions, therapists are advised to use short, specific and clear questions to keep the client focussed on their problem. They are also advised to ask questions in the present tense, as a disruption occurs, in order to help the client notice and verbally elaborate upon a background thought (Carey, 2006).

Asking about disruptions overlaps with various techniques in other psychotherapies; including identifying and catching maladaptive thoughts in CBT (Beck, 1979), highlighting and coaching clients to become aware of emotions in Emotion Focused Therapy (Greenberg, 2004), and bringing attention to the present moment in Mindfulness based exercises (Rappaport, 2014). Through analysing 'asking about disruptions' in MOL, it is possible to explore and refine the therapy, as well as understand the important components of related techniques in other psychological therapies. 
Conversation Analysis (CA) provides an ideal framework to investigate asking about disruptions. CA studies real-world, naturally occurring conversation: talk-ininteraction (Drew, 2004). CA research has found talk to be highly organised; speakers use and orient to shared practices and sequences within interaction, and it is through these that meaningful and coherent communication and action are possible (Drew, 2004; Sutherland, Peräkylä \& Elliot, 2014). Institutional talk, such as psychotherapy talk, derives from the same shared practices, but has its own distinctive features, activities and goals. Rights to certain actions may be circumscribed, such as questions being principally used by the therapist and not the client (Vehviläinen, Peräkylä, Antaki \& Leudar, 2008). While 'pure CA' focusses on investigating the practices of ordinary conversation, 'applied CA' extends this learning to the larger structures and institutions within which this talk is situated. Applied CA aims to investigate, analyse and improve the use of this talk (Antaki, 2011; ten Have, 2007), and as such has been used for this study.

There is a growing body of CA research on psychotherapeutic practices, including therapist interpretations (Vehviläinen, 2008), client resistance (Macmartin, 2008) and formulations (Antaki, 2008). It has been used within a number of different therapeutic approaches, including cognitive behavioural, person-centred and psychodynamic therapies (Fitzgerald, 2013; Peräkylä, Antaki, Vehviläinen \& Leudar, 2008). CA describes surface-level, observable practice, and does not attempt to describe or infer 'internal' processes or experiences within the client (Deppermann, 
2012). It offers a data-driven and inductive method that is context sensitive, and captures the variability and unpredictability of real-life clinical practice. CA makes it possible to study how action in psychotherapy is getting done; that is, how practices work to bring about a favourable change in the way clients understand and relate to their experiences (Madill, Widdicombe \& Barkham, 2001; Peräkylä et al., 2008). It provides a perspective to process research from outside psychotherapy institutions (Madill et al., 2001), based solely on how conversation and interaction work (Fitzgerald, 2013; Peräkylä, 2004). Arguably, a focus on quantitative outcome measures and efficacy debates have led to ineffective guidance for clinical practice (Kazdin, 2008; Fitzgerald, 2013), and often therapeutic training overlooks the use of language and conversational practices (Fitzgerald, 2013). By contrast, CA findings can be used by therapists to examine and reflect on their own talk, in order to enhance their practice (Fitzgerald, 2013).

Investigating a single component of therapy in detail is one way of exploring how and why psychotherapy does or does not work. There is growing evidence regarding the efficacy of $\mathrm{MOL}$ but the technique of asking about disruptions has not been studied in detail. As such, the aims of this research are:

(1) To identify instances of asking about disruptions, describing their form and function in real life therapeutic encounters

(2) To investigate client responses to asking about disruptions 


\section{METHOD}

\section{Participants and data}

First sessions of MOL therapy were audio-recorded by four therapists for 12 participants; eight female, four male, aged 18 to 41 years. The majority were categorised as White British, with one White Irish and one French participant who spoke English. First sessions of therapy were chosen, as this allowed maximum sampling of different participants, whilst ensuring homogeneity and consistency in the stage of therapy. This is important due to the potential for clients to become better at recognising their own disruptions as they progress through therapy (Carey, 2006). The therapists were: a male clinical psychologist in his late 30s, who practices, trains and researches MOL; three female research assistants of different ethnic origins who were in their 20 s. Each had a first degree in psychology and were employed to provide a psychological therapy under supervision. All therapists received MOL training and attended weekly therapeutic supervision with experienced MOL therapists. Data were collected from new referrals into six General Practitioner surgeries within a North West England Primary Care Mental Health Service. Participants were experiencing mental health problems of mild to moderate severity, such as depression, anxiety and stress-related disorders, within the Primary Care 
stepped-care model, a model in which the most effective but least resource intensive treatment is delivered to patients first (National Institute for Health and Care Excellence [NICE], 2011). Clients provided informed written consent to take part in an MOL open trial, evaluating the feasibility of the therapy within a Primary Care setting and testing whether it worked in a way consistent with the theory (Lansbergen, 2010; NHS Research Ethics Committee reference number 09/H1016/105, Research \& Development number 2009/116). Participants consented to have sessions audio-recorded, shared with the research team, and stored confidentially for up to ten years so that they could be used in future research studies. Sessions ranged from 19:10 to $60: 08$ minutes, with a total running time of $386: 51$. The recordings were transcribed verbatim by the research assistants and all data anonymised, with identifying details replaced by pseudonyms.

Procedure

A series of meetings were held to analyse the data to identify instances of asking about disruptions, and their regular features. The first author subsequently listened repeatedly to all available recordings and identified 54 instances of asking about disruptions, in ten of the 12 sessions. These instances were transcribed in detail using CA conventions (Jefferson, 2004; see Table 1), which represents talk as it was 
originally spoken, including details such as pauses, intonation, overlapping talk and pitch (Clayman, 2013; Sutherland, et al., 2014). The instances were discussed by the research team in a series of subsequent meetings, and investigated for interactional patterns. Transcripts and original audio recordings were consulted throughout the analysis, with the identified instances re-read and re-listened to and intended actions, consequences and subsequent responses to turns investigated.

\section{ANALYSIS}

The vast majority of instances identified received responses that can be described as consistent with the aims of MOL; questions encouraged further talk from the client, which was focused on the client's problem, and projected a shift in the style of the client's talk, from evaluative talk to meta-level commentary. This commentary included meta-assessments or evaluations of clients' prior talk, thoughts or actions. The analysis describes the design and timing of these questions, with a disruption not fitting MOL theory and a client influencing her own disruption, also presented.

How to ask about disruptions When interacting in any context, individuals take it in turns to talk (Drew, 2013). These turns are designed to perform and achieve specific actions, with turn design referring to the verbal and linguistic features used (Drew, 2013). Prior to extract 1 the client has been talking about burdening other people with her problems. The therapist asks about the disruption in line 8 , this is highlighted by the side arrow and bold type. 


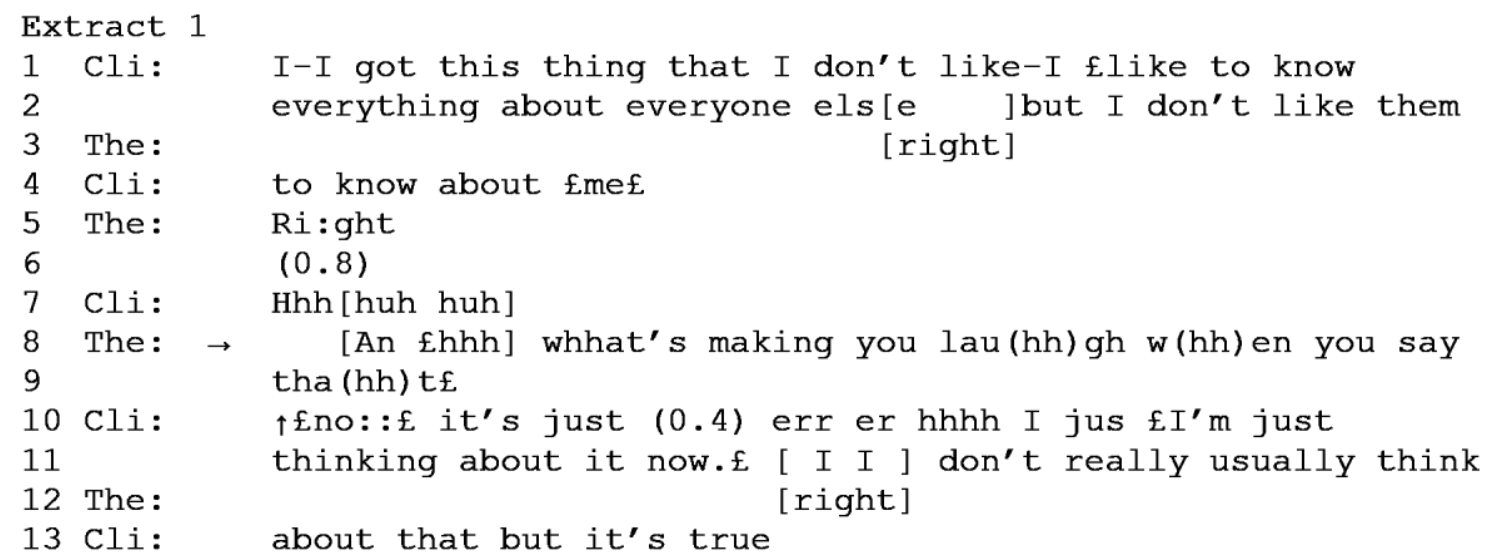

The disruption identified by the therapist in his question (laughter) occurs in line seven, with smiley voice (the "£" symbol in the transcript) in line four, leading to laughter in line seven (the "hhh"s, and "huh huh", with the latter a phonetic reflection of how the client's laughter sounds). The therapist asks about this disruption using a wh-question, as was the case for all questions about disruptions identified in the corpus. Wh-questions usually begin with 'what', 'where', 'when' or 'who' and project the receipt of specific types of responses, for example a 'where' question projects reference to a place in its response (Schegloff \& Lerner, 2009). In this case, the 'what' question projects an account or explanation for the identified disruption. This design is explicitly suited to the goals of MOL therapy, as it projects the receipt of responses consistent with two of its aims: encouraging further talk, with this talk focused on the client's disruption and problem. The question uses present tense and asks about the disruption as it is 
happening, in the here and now ("what's making you laugh.") It also specifically indexes the precise part of the talk that the therapist is asking about ("when you say that,") with "that" linking it back to the prior turn.

The response received (lines 10-13) is consistent with MOL aims; the client answers the therapist's question by providing an account and explanation for her laugh. There is evaluative talk before the question at line two ("I don't like them to know about me") and this talk continues after the question, with the client making an assessment of her prior talk at line 11 (“I don't really usually think about that but it's true.") Evaluative talk often contains assessments or appraisals and is used to express opinions or knowledge (Wiggins \& Potter, 2003), in contrast to descriptive talk which omits these. In CA, assessments indicate an evaluation of a referent, event or experience (Goodwin \& Goodwin, 1992), and are common in psychotherapy (Voutilainen, Rossano \& Peräkylä, 2018). Here, the assessment also represents a shift to meta-talk. Meta-talk refers to talk about talk, such as referring to aspects, events or actions of talk (Schiffrin, 1980). In this case, meta-talk refers to the client assessing her own prior talk in line 11 ("thinking about it now," followed by the assessment). While CA brackets cognitive processes (Deppermann, 2012), the presence of this metatalk is observational evidence of the client reflecting on her previous talk, and from a PCT perspective could indicate evidence of the client moving up levels of the hierarchies.

Extract 1 is, therefore, an example adherent to MOL. The question keeps the client in the present moment and makes it clear what kind of answer is required. It 
elicits a response that is consistent with the aims of MOL: encouraging further talk, this talk is focused on her problem, and it projects a shift to meta-level commentary with an assessment of prior talk. As such, MOL training which suggests using short, specific and clear questions asked in the present tense, is supported by this extract.

Conversely, the following extract outlines an instance that receives a response less consistent with the aims of MOL. Prior to extract two the client is talking about thoughts of taking her own life, and how important her Mum and grandchildren are to her.

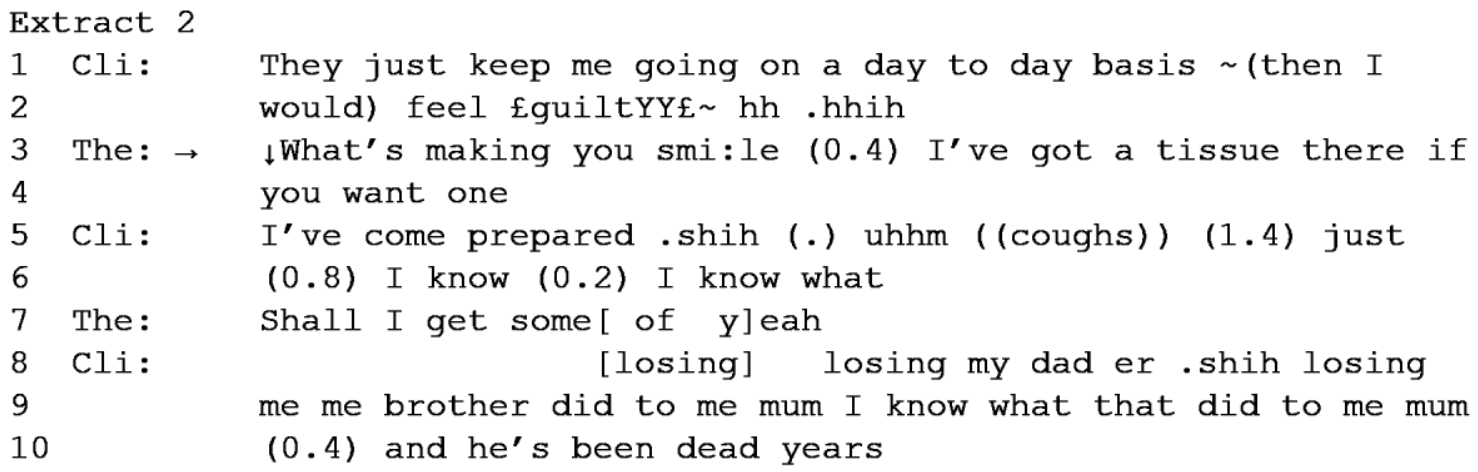

Based on the naming of the disruption in line three, the therapist is asking about the smile transcribed as smiley voice $(£)$ in line two. The design of the first half of the therapist's turn is similar to extract one, a turn constructional unit (TCU) that verbally names the disruption. TCUs are the basic 'building blocks' of talk and together form complete turns (Clayman, 2013). The client responds in line five to the second TCU of 
the therapist's turn, regarding tissues. The client then appears to continue her turn from line two and describe her problem. In a turn with two separate utterances, the second one will typically be responded to first, ensuring contiguity; that is, connectedness to the prior turn (Drew, 2004; Sacks, 1987). Therefore, while the interaction continues and the client describes her problem, unlike the previous extract she does not directly address the question about the disruption by providing an account or explanation. Additionally, there is no evaluation or assessment of prior talk and no shift to meta-talk. This extract provides an example where the therapist's question does not lead to the ideal shift in style of talk, suggesting no shift in perspective or moving up levels of hierarchies.

When to ask about disruptions

A common pattern of turn taking was identified in all except one of the 54 instances. At the end of a TCU, there is a 'transition relevance places' (TRP), indicated through intonation, complete actions and grammar. TRPs project or specify a place where the speaker's turn could realistically be finished and it is possible for the next speaker to take a turn (Clayman, 2013). The pattern identified in the vast majority of extracts can be summarised as:

(1) Client turn with disruption in or as the final TCU

(2) Therapist question regarding the disruption in the next TRP, or in slight overlap with the prior turn 
(3) Client response

When re-examining extract one, it is evident that the therapist starts her question in overlap with the laugh identified in the question (as indicated by the square brackets in lines seven and eight). This slight overlap is a common feature of transitions, as recipients project the completion of TCUs. Asking the question in the next available TRP (or in overlap, as here) allows for smooth and orderly turn taking, and for conversation to flow and progress coherently (Clayman, 2013; Schegloff, 2004). Even in extract two, despite receiving a response that is less consistent with the aims of $\mathrm{MOL}$, the therapist asks his question in the next TRP immediately following the disruption (the smile voice at the end of line two). These findings support practice suggested in MOL training, in which therapists are advised to ask about disruptions as soon as they occur, in order to keep the client's awareness on the disruption in the moment (Carey, 2006). In the large majority of instances this pattern led to responses that were consistent with the aims of MOL.

The significance of this pattern of turn-taking is exemplified by the one example that deviates from it. Prior to the interaction in extract three, the client is discussing frustrations with her partner. 


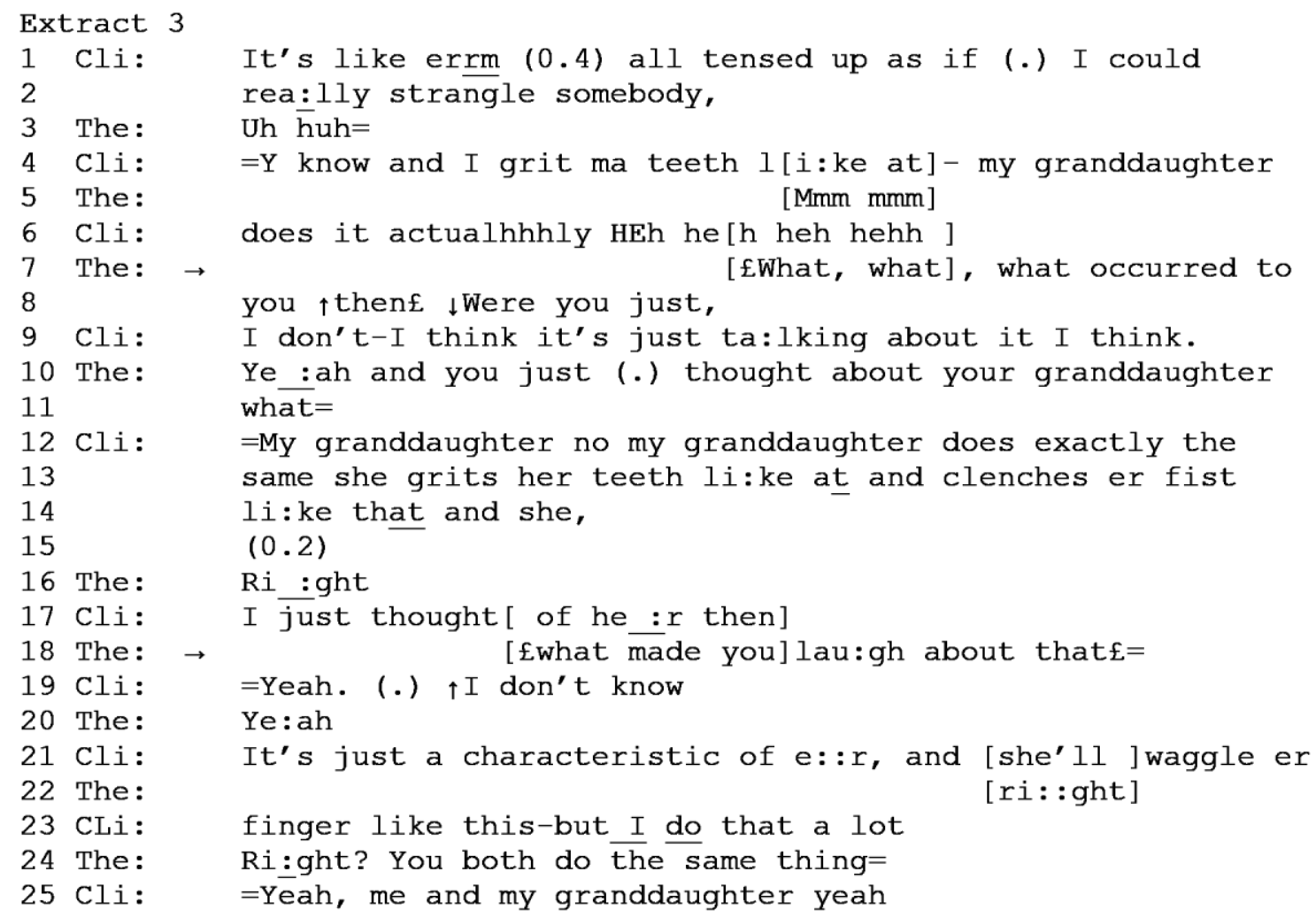

This extract contains two instances of the therapist asking about disruptions. Although the question at lines seven to eight does not verbally label a disruption, it could potentially be asking about a disruption in the immediately prior TCU due to the deixis "then" at line seven. It is unclear precisely what the disruption is, although it could feasibly be referring to the action of gritted teeth in line four, or the laughter in line six (the use of the word laughter in the subsequent question at line 18 suggests the latter). The words "occurred" and "then" on lines seven and eight also indicate past tense, as opposed to previous questions that have used present tense. The client 
provides a meta-level assessment of her prior talk at line nine ("it's just talking about I think"), before describing the physical actions her granddaughter sometimes displays, and a further meta-comment targeting the disruption ("then") at line 17 ("I just thought of her then"). What is different about this extract is the therapist's 'follow up' style question at line 18. This indicates that the therapist has not yet received what he treats as an adequate response to his first question (one which provides an account for why the client laughed). The question at line 18 is the only example identified in the corpus that asks about a disruption not in the immediately prior TCU. The response does provide an account for the laugh, and the client makes a self-assessment at line 23 ("I do that a lot"). This self-assessment continues to focus on the prior physical action rather than the focus on thought processes seen in the previous extract ("thinking about it now" in extract 1). As such this provides less evidence of the client moving up levels of perceptual hierarchies and provides an additional example where the therapist's question does not lead to the ideal shift in style of reflection.

This follow-up question indicates a lack of shared understanding between therapist and client regarding the disruption being asked about, and points to the positives of therapists verbally labelling the disruption within their question. The extract also provides evidence against trying to 'follow-up' and ask about disruptions a number of turns after they have occurred, due to its impact on the shift in style of talk. Again, this indicates a lack of adherence to the MOL approach and supports the suggestion 
that therapists should ask about disruptions as soon as they occur (Carey, 2006), and in the present tense (Carey, 2008).

\section{Therapist influence}

One instance was identified in which the therapist influenced the disruption he then asked about. In the following extract the client is discussing problems at work.

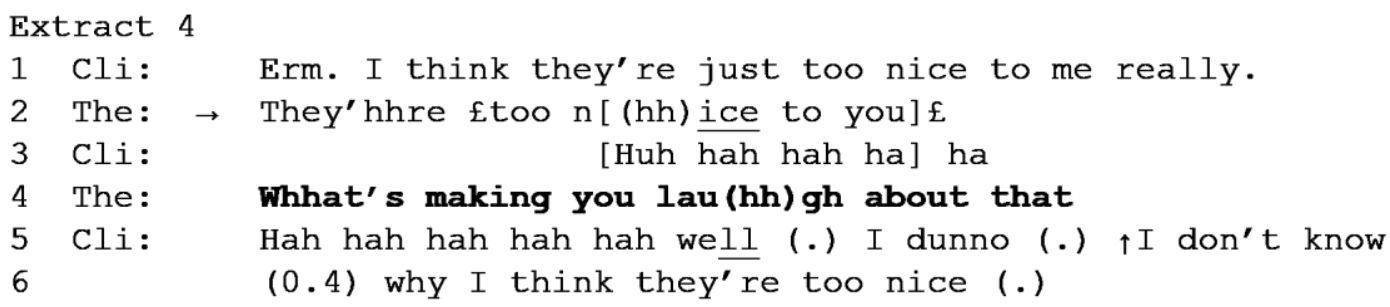

In line four, the therapist asks the client about her laughter, which is visible in the transcript at line 3. However, the laughter actually starts before this, as indicated by the laughter particles (hh) and smiley voice $(£)$ in the therapist's talk in line two. CA studies have found that laughter and smiley voice can invite reciprocal laughter from others (Holt, 2013). Therefore, it is possible that the therapist actually precipitates the disruption that he then asks about, and that the client's laughter in line three is simply responding to the therapist's laughter in line two.

While this response meets the aims of MOL (it encourages further talk focused on her problem, including a meta-level assessment: "I don't know why I think they're too nice,") with this example it could be argued that the therapist influences the 
occurrence of the disruption. This aspect of the interaction makes it difficult to view the disruption as something that naturally occurred while the client was speaking, as in the MOL definition (Carey, 2006).

\section{Client influence}

One instance was identified in which the client notices her own disruption. Prior to this extract the client is talking about taking other people's advice over her own (what "this" in line one is referring to).

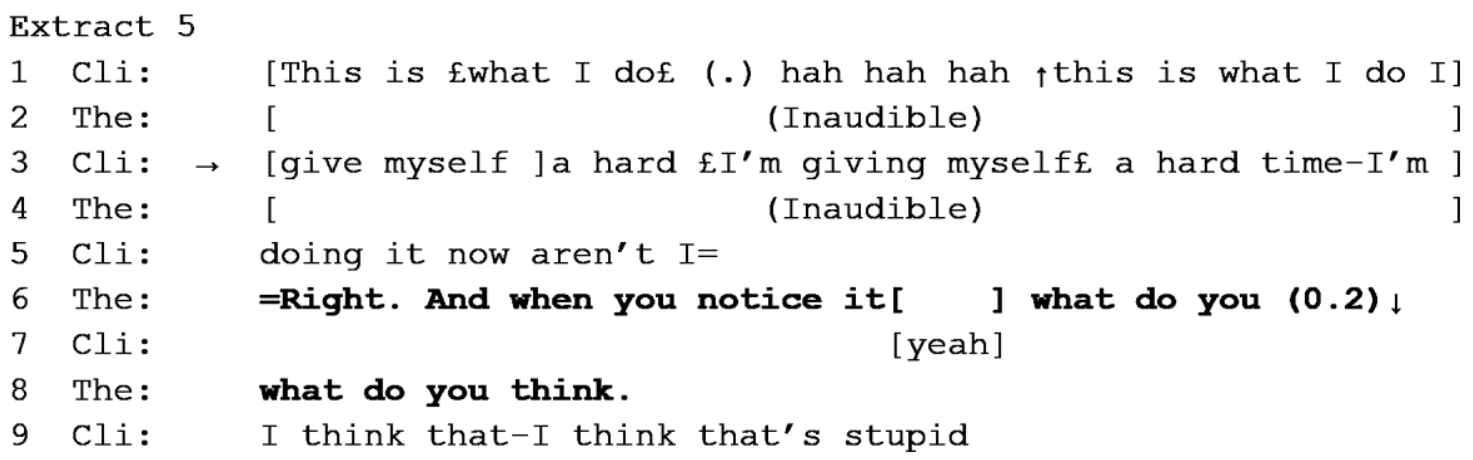

At line one, the client is reflecting on her actions by noting a predictable pattern in her behaviour ("this is what I do"). In line three, she initiates a self-repair that shifts from the general assessment ("I give myself a hard") to the current, here-and-now, meta-level noticing ("I'm giving myself a hard time"), before seeking agreement from the therapist: ("I'm doing it now aren't I.", lines three and five). This extract is distinctive, 
as it demonstrates a client already doing the therapeutic work that MOL aims to achieve: reflecting on and providing a meta-level assessment of her own talk and actions, before any intervention from the therapist. At lines six and eight, the therapist asks his question about the disruption (the client's self-repair and meta-level noticing in line three), which prompts further self-reflective commentary from the client at a metalevel ("I think that's stupid" line nine).

In MOL terms this may indicate shifting awareness up a further level of the perceptual hierarchy. This response is therefore consistent with the aims of MOL, and could be said to constitute an 'ideal' case where a client has learned to integrate a therapeutically relevant, MOL practice into her own actions. The sole difference here is that the client is already providing meta-commentary on her own talk before any question by the therapist, which then influences the disruption the therapist asks about.

\section{DISCUSSION}

This paper presents an analysis of a single component of MOL therapy, in order to explore how the therapy works. Both of the research aims have been met:

(1) Instances of asking about disruptions have been presented and described regarding their form and function in real-life therapeutic encounters

(2) Responses to these instances have been investigated and presented in terms of their degree of adherence to the MOL approach 
While CA cannot infer internal processes, the interactional findings outlined above reflect a number of aspects of PCT. Furthermore, these can be extended to the institutional setting in question (psychotherapy), and used to inform clinical practice, as is the aim of applied CA. All questions about disruptions were wh-questions, which project the receipt of responses consistent with two of MOLs aims: encouraging further talk, with talk focused on the client's disruption and problem, and a shift to meta-level commentary. Questions asked in a clear, timely, concise and explicit way were found to receive these responses considered consistent with MOL theory, and as such are recommended as best practice. Conversely, in extract two, issues of contiguity contributed towards a response inconsistent with the above aims, further supporting the recommendations outlined above.

Regarding question timing, all except one of the 54 instances fit the same pattern, with responses consistent with MOL's aims found when the questions about the disruption were asked following the TRP (or in slight overlap). This fits MOL guidance that asking about disruptions as soon as they occur ensures the client is fully able to recall the disruption and any surrounding background thoughts (Carey, 2009; Carey et al., 2015). Again, this is recommended as best practice. Further support of this practice was found in the one exception to this pattern, (extract 3), in which asking about a disruption that had occurred a number of turns earlier received a response inconsistent with MOL aims. 
The presence of meta-assessments and evaluations of prior talk, thoughts and actions in responses consistent with the aims of MOL also supports PCT. Parallels can be drawn between the definitions of meta-talk, assessments and the MOL definition of what happens when asking about disruptions. The shift to meta-level commentary is observational evidence of clients reflecting on their previous talk, and from a PCT perspective indicates evidence of clients moving up levels of perceptual hierarchies, which is the ultimate purpose of MOL (Carey, 2009). This paper provides interactional evidence in support of this therapeutic change process.

While CA cannot, and the MOL therapist would not in practice, infer internal practices, we could provide some hypotheses based on PCT of the clients' internal processes, with the proviso that a definitive interpretation of another person's experiences is not possible. Taking extract one as an example, prior to the therapist's question about the disruption, the client appears to be considering low level goals such as the topics of conversations with friends (see supplemental material for full extract). Following the therapist's question, she makes an assessment and appears to be considering higher level goals such as how these conversations relate to her character (such as, being nosey; being selfish). We might hypothesise from the extract that one conflict involves wanting to hear about other people's problems at the same time as not wanting to reciprocate and share her own problems with other people. Following an insight into this, she might prioritise one of these goals, for example in terms of how much of herself she starts to share in subsequent conversations. 
Similarities can be drawn between the current findings and those presented by Muntigl and Horvath (2014), who use the term 'noticings' to describe a therapist drawing attention to something that has just occurred during client's talk, such as verbal and nonverbal features. Noticings were used to focus client's talk on their here-and-now experience, and progressed the interaction by either prompting further talk around the client's affectual stance or by drawing attention to a new feature of the prior talk (Muntigl \& Horvath, 2014). Both noticings and asking about disruptions place emphasis on clients' present moment experience, and while noticings facilitate the progressivity of emotion talk (Muntigl \& Horvath, 2014), asking about disruptions appears to facilitate the progression of self-reflective, meta-level evaluative talk.

A possible reciprocal influence of the therapist has been outlined in extract four, in which the therapist asked about a disruption he may have influenced. Disruptions are theorised to relate to the fluid relationship between awareness and background and foreground thoughts, occurring naturally as clients speak (Carey, 2006). MOL is clientled, with therapists advised to maintain curiosity, and not guide, lead, or direct (Carey, 2006). While it may not be possible to completely evade this practice of influencing disruptions in conversation, it highlights a potential challenge for therapists to be aware of. Additionally, a number of instances were excluded from analysis due to interpretation being inferred by the therapist, for example 'why is that funny?' rather than 'what is happening when you laugh about that?' Reducing therapist influence is 
desired due to the client-led focus of therapy, and so the practices above should be avoided.

Lastly a client noticing her own disruption was presented, which links to the notion of the fluid relation between background and foreground thoughts. MOL aims to enable clients to develop greater mental flexibility, and become better at recognising their own background thoughts, goals and conflicts (Carey, 2006). Interactionally this might be evidenced by clients assessing their own talk, actions and thoughts in the way shown here.

Limitations of this research include the sole use of audio recordings. Some instances were excluded from analysis due to the therapist referring to a disruption that was not verbally named and could not be recognised from the recording. As such, future research would benefit from the use of video recordings to ensure that important interactional features such as facial expressions and body language are not missed (Mondada, 2013). Secondly, although a decision was made to use the client's first sessions of MOL, this precluded the possibility for investigating the process of asking about disruptions longitudinally across a number of sessions, in order to explore whether clients become better at recognising their disruptions as they progress through therapy.

The suitability of CA to process research was highlighted in the introduction; however, there are a number of restrictions. It is not within the scope of CA to make cognitive connections with the interactional practices it explicates (Potter \& Edwards, 
2013) and combining CA and psychotherapy can be difficult when it comes to notions of internal cognition (Peräkylä, 2004). However, while MOL is informed by PCT, and so assumes behaviour to be the means of controlling internal perceptions, in practice the therapist's role is to observe the client's interactions and ask about disruptions. As such, neither MOL or CA aim to infer an understanding of an individual's cognitions or internal states at the time of therapy. Therefore, CA complements the MOL approach in terms of providing useful insights into practices relating to the processes of the interaction, which can then be related at a more abstract level to PCT.

These CA findings empirically support practices suggested by PCT. They demonstrate how process research can contribute to improving clinical practice (Kazdin, 2008), and how therapists might draw on 'stocks of interactional knowledge' (SIKS) (Peräkylä \& Vehviläinen, 2003). SIKs refers to how institutional talk may be influenced by theories and ideas regarding their interaction with clients. These theories transcend training, practice and discourse and often do not resonate with the terminology used to describe language in CA (Peräkylä \& Vehviläinen, 2003). CA investigates how these more abstract theories occur within an interaction, and in trying to bridge the gap between theory and practice, can been used to correct, add detail to or expand assumptions held by SIKs (Peräkylä \& Vehviläinen, 2003). We can summarise the overall contributions of this paper using these SIKS, and here, CA 
findings and process research can be used to refine therapists' approach and timing of asking about disruptions.

\section{CONCLUSION}

MOL therapists asking about disruptions has been found to encourage further talk from clients that is focused on their problem and the disruption. The shift to meta-talk and evaluation that was observed in these responses indicates observational evidence of clients moving up levels of their perceptual hierarchies. These responses were best achieved when therapists used clear, concise and explicit wh-questions, and asked about the disruption in the following TRP or in overlap with this. Finally, therapists should be aware of the possibility that they may influence the presence of disruptions, or for clients to recognise their own disruptions which is an aim of MOL therapy. These findings indicate SIKs which therapists may rely upon when delivering MOL therapy sessions. To the extent that other therapies have similar goals to an MOL therapist, these other approaches and techniques may also be maximised by timing questions soon after changes in speech, mannerism or demeanour are noticed, and by using open, wh-questions in the present tense. Doing so will enable therapists of any modality to catch, shift and sustain client's awareness on to the areas they are experiencing conflict and difficulty, a process found to be key to a wide range of psychotherapies (Mansell \& Higginson, 2016; Carey, 2011). Examining this mechanism of change in detail, refines therapy, practice and ultimately, client care (Kazdin, 2008; Pfeifer \& Strunk, 2015). 


\section{REFERENCES}

Antaki, C. (2008). Formulations in psychotherapy. In A. Peräkylä, C. Antaki, S. Vehviläinen and I. Leudar (Eds.) Conversation Analysis and Psychotherapy (pp26-42), Cambridge, United Kingdom: Cambridge University Press.

Antaki, C. (2011). Six kinds of applied conversation analysis. In Applied conversation analysis (pp. 1-14). London, United Kingdom: Palgrave Macmillan.

Beck, A. T. (Ed.). (1979). Cognitive therapy of depression. New York, NY: Guilford Press.

Carey, T. A. (2006). The method of levels: How to do psychotherapy without getting in the way. Hayward, California: Living Control Systems Publishing.

Carey, T. A. (2008). Hold That Thought! Two Steps to Effective Counseling and Psychotherapy with the Method of Levels. St Louis, Missouri: New View Publishing. 
Carey, T. A. (2009). Dancing with distress: helping people transform psychological problems with the method of levels two-step. The Cognitive Behaviour Therapist, 167-177. https://doi.org/10.1017/S1754470X08000147

Carey, T. A. (2011). Exposure and reorganization: The what and how of effective psychotherapy. Clinical psychology review, 31, 236-248.

https://doi.org/10.1016/j.cpr.2010.04.004

Carey, T. A., Carey, M., Mullan, R. J., Spratt, C. G., \& Spratt, M. B. (2009). Assessing the statistical and personal significance of the method of levels. Behavioural and Cognitive Psychotherapy, 37, 311-324.

https://doi.org/10.1017/S1352465809005232

Carey, T. A., Mansell, W. \& Tai, S. (2015). Principles-based counselling and psychotherapy: A Method of Levels Approach. Oxford, United Kingdom: Routledge.

Carey, T. A., \& Mullan, R. J. (2008). Evaluating the method of levels. Counselling Psychology Quarterly, 21, 247-256.

https://doi.org/10.1080/09515070802396012

Carey, T. A., Tai, S. J., \& Stiles, W. B. (2013). Effective and efficient: Using patient-led appointment scheduling in routine mental health practice in remote Australia. Professional Psychology: Research and Practice, 44, 405. https://doi:10.1037/a0035038 
Clayman, S. E. (2013) Turn-constructional units and the transition-relevance place. In J. Sidnell \& T. Stivers (Eds.). Handbook of Conversation Analysis (Vol. 121, pp150-16). Chichester, United Kingdom: Wiley.

Deppermann, A. (2012). How does 'cognition' matter to the analysis of talk-ininteraction? Language Sciences, 34, 746-767. https://doi.org/10.1016/j.langsci.2012.04.013

Drew, P. (2004). Conversation Analysis. In K. L Fitch, R. E. Sanders (Eds.), Handbook of Language and Social Interaction (pp71-102). New York, NY: Psychology Press.

Drew, P. (2013). Turn Design. In J. Sidnell \& T. Stivers (Eds.). Handbook of Conversation Analysis (Vol. 121) (pp131-149). Chichester, United Kingdom: Wiley.

Elliott, R. (2010). Psychotherapy change process research: Realizing the promise. Psychotherapy Research, 20, 123-135. https://doi.org/10.1080/10503300903470743

Fitzgerald, P. (2013). Therapy talk: Conversation analysis in practice. Basingstoke, United Kingdom: Palgrave Macmillan.

Goodwin, C., \& Goodwin, M. H. (1992). Assessments and the construction of context. In A. Duranti \& C. Goodwin (Eds.), Rethinking Context: Language as an 
Interactive Phenomenon (No. 11, pp147-189). Cambridge, United Kingdom: Cambridge University Press.

Greenberg, L. S. (2004). Emotion-focused therapy. Clinical Psychology \&

Psychotherapy, 11, 3-16. https://doi.org/10.1002/cpp.388

Holt, E. (2013). On the Nature of "Laughables": Laughter as a Response to Overdone

Figurative Phrases. Pragmatics, 21. https://doi.org/10.1075/prag.21.3.05hol

Jefferson, G. (2004). Glossary of transcript symbols with an introduction. In G. H.

Lerner (Ed.), Conversation Analysis: Studies from the First Generation (pp. 13-

31). Amsterdam/ Philadelphia: John Benjamins Publishing Company.

Kazdin, A. E. (2008). Evidence-based treatment and practice: new opportunities to bridge clinical research and practice, enhance the knowledge base, and improve patient care. American Psychologist, 63, 146-59.

https://DOI:10.1037/0003-066X.63.3.146

Lansbergen, M. (2010). Pilot Evaluation of Method of Levels Cognitive Therapy. (Unpublished clinical psychology doctoral thesis). University of Manchester, Manchester, United Kingdom.

MacMartin, C. (2008). Resisting optimistic questions in narrative and solution-focused therapies. In A. Peräkylä, C. Antaki, S. Vehviläinen and I. Leudar (Eds.) Conversation Analysis and Psychotherapy (pp80-99), Cambridge, United Kingdom: Cambridge University Press. 
Madill, A., Widdicombe, S., \& Barkham, M. (2001). The potential of conversation analysis for psychotherapy research. The Counseling Psychologist, 29, 413434. https://doi.org/10.1177/0011000001293006

Mansell, W. \& Higginson, S. (2016). The Depth and Duration of Awareness Coding Scheme (D-DACS) Manual. Retrieved from: https://www.researchgate.net/publication/289522660 The Depth and Duratio $\underline{n \text { of Awareness Coding Scheme D-DACS Manual }}$

Mondoda, L. (2013). The Conversation Analytic Approach to Data Collection. In J. Sidnell \& T. Stivers (Eds.). Handbook of Conversation analysis (Vol. 121) (pp32-56) Chichester, United Kingdom: Wiley.

Muntigl, P., \& Horvath, A. O. (2014). "I can see some sadness in your eyes": When experiential therapists notice a client's affectual display. Research on Language and Social Interaction, 47, 89-108. https://doi.org/10.1080/08351813.2014.900212

National Institute for Health and Care Excellence. (2011). Common mental health problems: identification and pathways to care. Retrieved from https://www.nice.org.uk/guidance/cg123

Peräkylä, A., \& Vehviläinen S. (2003). Conversation analysis and the professional stocks of interactional knowledge. Discourse \& Society, 14, 727-750. https://doi.org/10.1177/09579265030146003 
Peräkylä, A., Antaki, C., Vehviläinen, S., \& Leudar, I. (Eds.). (2008). Conversation Analysis and Psychotherapy. Cambridge, United Kingdom: Cambridge University Press.

Pfeifer, B. J., \& Strunk, D. R. (2015). A primer on psychotherapy process research: a review of cognitive therapy of depression. Australian Psychologist, 50, 411-415. https://doi.org/10.1111/ap.12147

Pomerantz, A. \& Fehr, B. J. (1997). Conversation Analysis: An approach to the study of social action as sense making practices. In T. A. van Dijk (Ed), Discourse as social interaction. London, United Kingdom: Sage Ltd.

Potter, J. \& Edwards, D. (2013) Conversation Analysis and Psychology. In, Sidnell, J., \& Stivers, T. (Eds.). The Handbook of Conversation Analysis (Vol. 121, pp70172) Chichester, United Kingdom: Wiley.

Powers, W. T. (1973). Behavior: The control of perception. Chicago: Aldine.

Powers, W. T. (2009). PCT and MOL: a brief history of Perceptual Control Theory and the Method of Levels. The Cognitive Behaviour Therapist, 2, 118-122. https://doi.org/10.1017/S1754470X08000111

Rappaport, L (2014). Introduction. In L. Rappaport (Eds.). Mindfulness and the Art Therapies: Theory and Practice (pp15-21). London, United Kingdom: Jessica Kingsley Publishers. 
Sacks, H. (1987). On the preferences for agreement and contiguity in sequences in conversation. In G. Button, G, \& J. R. Lee (Eds.). Talk and Social Organisation (Vol. 1, pp54-69) Clevedon, United Kingdom: Multilingual Matters.

Schegloff, E. A. (2004). Increments. Unpublished manuscript.

Schegloff, E. A., \& Lerner, G. H. (2009). Beginning to respond: Well-prefaced responses to wh-questions. Research on Language and Social Interaction, 42, 91-115. https://doi.org/10.1080/08351810902864511

Schiffrin, D. (1980). Meta-talk: Organizational and evaluative brackets in discourse. Sociological Inquiry, 50, 199-236. https://doi.org/10.1111/j.1475$\underline{682 X .1980 . t b 00021 . x}$

Spring, B. (2007). Evidence-based practice in clinical psychology: What it is, why it matters; what you need to know. Journal of Clinical Psychology, 63, 611-631. https://DOI:10.1002/jclp.20373

Sutherland, O., Peräkylä, A., \& Elliott, R. (2014). Conversation analysis of the twochair self-soothing task in emotion-focused therapy. Psychotherapy Research, 24, 738-751. https://doi:10.1080/10503307.2014.885146.

ten Have, P (2007). Doing Conversation Analysis: A practical guide. London, United Kingdom: Sage Ltd.

Vehviläinen, S. (2008). Identifying and managing resistance in psychoanalytic interaction. In A. Peräkylä, C. Antaki, S. Vehviläinen and I. Leudar (Eds.) 
Conversation Analysis and Psychotherapy (pp120-138), Cambridge, United Kingdom: Cambridge University Press.

Vehviläinen, S, Peräkylä, A, Antaki, C, and Leudar, I (2008) A review of the conversational practices of psychotherapy. In A. Peräkylä, C. Antaki, S. Vehviläinen and I. Leudar (Eds.) Conversation Analysis and Psychotherapy (pp188-197), Cambridge, United Kingdom: Cambridge University Press.

Voutilainen, L., Rossano, F., \& Peräkylä, A (2018) Conversation Analysis and Psychotherapeutic Change. In S. Pekarek Doehler, J. Wagner and E. González-Martínez (Edss) Longitudinal Studies on the Organization of Social Interaction (pp. 225-254), London, United Kingdom: Palgrave Macmillan.

Wiggins, S., \& Potter, J. (2003). Attitudes and evaluative practices: Category vs. item and subjective vs. objective constructions in everyday food assessments. British Journal of Social Psychology, 42, 513-531. https://doi.org/10.1348/014466603322595257

\section{TABLE 1}

Table 1. Conversation Analytic Transcription Conventions Antaki C (2002) An introductory tutorial in Conversation Analysis. Online at <http://www-staff.lboro.ac.uk/ ssca1/sitemenu.htm>. Accessed on 10/7/17 


\begin{tabular}{|c|c|}
\hline [ ] & The start and end of overlapping speech. \\
\hline$\uparrow \downarrow$ & $\begin{array}{l}\text { Marked pitch movement, over and above normal rhythms } \\
\text { of speech. }\end{array}$ \\
\hline$\rightarrow$ & $\begin{array}{l}\text { Draw attention to features of talk that are relevant } \\
\text { to the current analysis. }\end{array}$ \\
\hline Underlining & Indicates emphasis. \\
\hline CAPITALS & $\begin{array}{l}\text { Mark speech that is hearably louder than surrounding } \\
\text { speech. }\end{array}$ \\
\hline I know it, & Enclose hearably quieter speech. \\
\hline that's r*ight. & Asterisks precede a 'squeaky' vocal delivery. \\
\hline$(0.4)$ & $\begin{array}{l}\text { Pause in seconds (in this case, } 4 \text { tenths of a } \\
\text { second). }\end{array}$ \\
\hline$($. $)$ & A micropause, hearable but too short to measure. \\
\hline$(($ stoccato $))$ & $\begin{array}{l}\text { Additional comments from the transcriber, e.g. about } \\
\text { features of context or delivery. }\end{array}$ \\
\hline she wa: :nted & $\begin{array}{l}\text { Degrees of elongation of the prior sound; the more } \\
\text { colons, the more elongation. }\end{array}$ \\
\hline hhh & $\begin{array}{l}\text { Aspiration (out-breaths); proportionally as for } \\
\text { colons. }\end{array}$ \\
\hline. hhh & $\begin{array}{l}\text { Inspiration (in-breaths); proportionally as for } \\
\text { colons. }\end{array}$ \\
\hline Yeh, & 'Continuation' marker, speaker has not finished; \\
\hline$y^{\prime}$ know? & $\begin{array}{l}\text { Stronger, 'questioning' intonation, irrespective of } \\
\text { grammar. }\end{array}$ \\
\hline Yeh. & $\begin{array}{l}\text { Falling, stopping intonation irrespective of } \\
\text { grammar, and not necessarily followed by a pause. }\end{array}$ \\
\hline bu-u- & A cut-off of the preceding sound. \\
\hline
\end{tabular}




\begin{tabular}{|c|c|}
\hline$>$ he said< & $\begin{array}{l}\text { 'Greater than' and 'lesser than' signs enclose } \\
\text { speeded-up talk. Occasionally they are used the } \\
\text { other way round for slower talk. }\end{array}$ \\
\hline solid. $==$ We had & $\begin{array}{l}\text { 'Equals' signs mark the immediate 'latching' of } \\
\text { successive talk, whether of one or more speakers, } \\
\text { with no interval. }\end{array}$ \\
\hline heh heh & Voiced laughter. \\
\hline sto $(h) p$ i (h)t & $\begin{array}{l}\text { Laughter within speech is signalled by h's in round } \\
\text { brackets. }\end{array}$ \\
\hline .shih & Wet sniff. \\
\hline qrandson & Wobbly voice - enclosed by tildes. \\
\hline Huhh .hhih & $\begin{array}{l}\text { Sobbing - combinations of 'hhs', some with full } \\
\text { stops before them to indicate inhaled rather than } \\
\text { exhaled, many have voiced vowels. }\end{array}$ \\
\hline
\end{tabular}

\section{SUPPLEMENTAL MATERIAL}

Table to show how examples of CA transcripts may be interpreted based on PCT

\begin{tabular}{|l|l|}
\hline Disruption & $\begin{array}{l}\text { Theorised cognitive processes } \\
\text { according to PCT }\end{array}$ \\
\hline Extract 1 & $\begin{array}{l}\text { Low level goals prior to question about } \\
\text { disruption: smile voice in line } 19 \text { and } \\
\text { laughter in line } 22\end{array}$ \\
& $\begin{array}{l}\text { conversations with friends. } \\
\text { Higher level goals following question } \\
\text { about disruption: how these } \\
\text { conversations relate to her character. } \\
\text { Conflict maintaining distress: wanting to } \\
\text { hear about other people's problems } \\
\text { whilst not wanting to reciprocate and } \\
\text { share her own problems with other } \\
\text { people. }\end{array}$ \\
\hline
\end{tabular}




\begin{tabular}{|l|l|}
\hline & $\begin{array}{l}\text { Following insight in to this, she might } \\
\text { prioritise one of these goals to generate } \\
\text { change, e.g. how much she starts to } \\
\text { share in subsequent conversations. }\end{array}$ \\
\hline Extract 5 & $\begin{array}{l}\text { Higher levels goals and reflective talk } \\
\text { prior to question about disruption: } \\
\text { considering giving and taking her own } \\
\text { advice and how this impacts her. } \\
\text { Further higher levels goals following } \\
\text { question about disruption: making } \\
\text { decisions and changes based on these } \\
\text { realisations. } \\
\text { Conflict maintaining distress: feeling able } \\
\text { to give others advice, but unable to follow } \\
\text { this advice herself. } \\
\text { Following insight in this this, she might } \\
\text { generate changes regarding paying more } \\
\text { attention to the advice she gives and } \\
\text { implementing this in her own life, } \\
\text { something she explicitly states she is } \\
\text { going to do. }\end{array}$ \\
\hline
\end{tabular}

\section{CA transcriptions of above extracts}

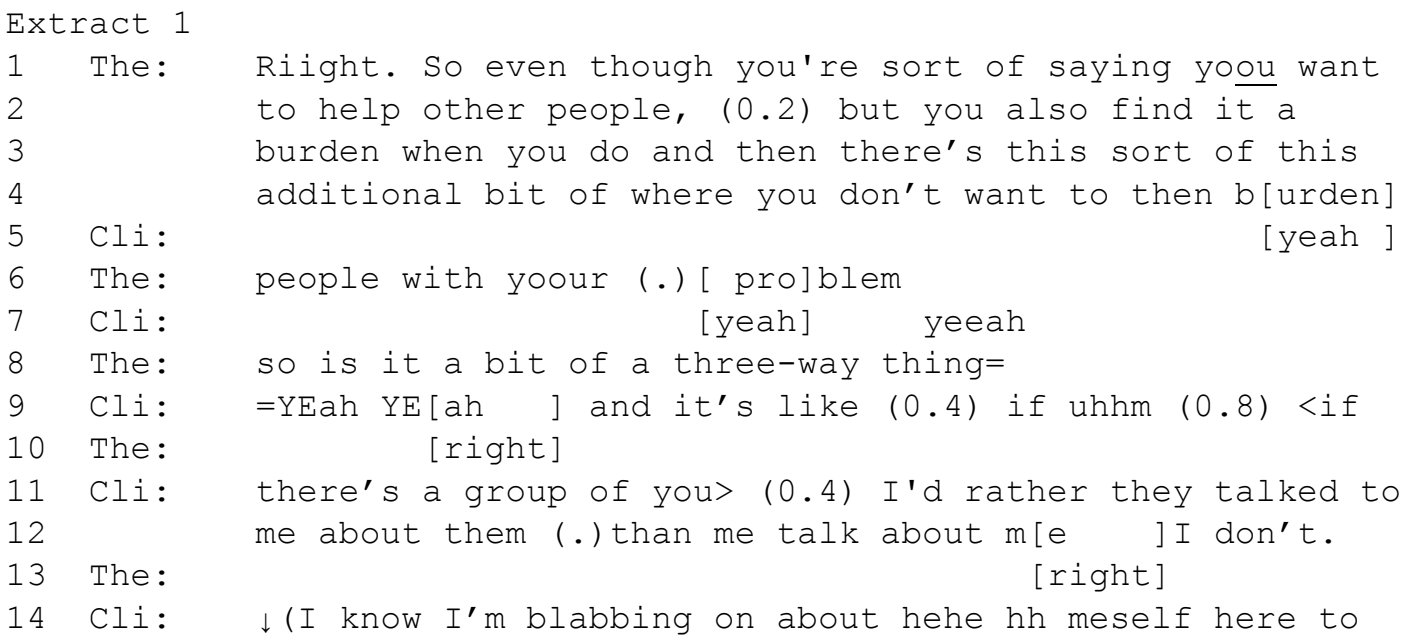


you) but I I I'd rather I don't like people to I-I got this thing that I don't like-I £like to know everything about everyone els[e] ]but I don't

The :

Cli:

The:

Cli:

The:

Cli:

The:

Cli:

The:

30

31

32

The:

Cli:

The:

Cli:

The:

$$
\text { [right] }
$$

like them to know about £me

Ri:ght

(0.8)

Hhh [huh huh]

[An $£ h h h]$ what's making you lau $(\mathrm{hh}) \mathrm{gh}$ w(hh)en you say tha $(\mathrm{hh}) \mathrm{t} £$

$\uparrow £$ no: : $£$ it's just (0.4) err er hhhh I jus $£ I^{\prime} m$ just thinking about it now. $£$ [ I I ] don't really usually think [right]

about that but it's true

Yeah, right. So you like knowing everything about everyone but at the same time you're finding it a burden when you know the problems $=$

Cli: =yeah I won't say I know-I I won't say I'm noosey

The: yeah

Cli: but people talk to $\mathrm{m}[\mathrm{e}$ ] and tell me the things about [yeah]

themselves but I don't like if someone started saying an prying into myy lif[e ] I don't like I don't want them

to [to know] in a way [yeah ]

[right ]

Right an an how does that feel saying you don't want them to knoow

Cli: Well it's a bit I think I I thinking about it I think it's a bit selfish reaally cos they're giving some of me them to me [and ] I'm not giving me (.) to them in a way

Extract 5
Cli:
$>I^{\prime} m$ giving myself a hard time now $<$ (.) about wh:yy I haven't thought about that-that $\overline{I^{\prime}}$ ve (0.6) .hhh $I^{\prime}$ ve not thought about this before. You see this is wha[t I do]o
The:
Cli: .hh HAH Hah hah ha (.) I've not thought about this before,
The:
Cli:
The:
$\rightarrow[g i v$

9 Cli: 
doing it now aren't $I=$

The:

=Right. And when you not 